\title{
PETA PUZZLE 3D BERBASIS MOBILE AUGMENTED REALITY SEBAGAI PROTOTIPE MEDIA PEMBELAJARAN GEOGRAFI Rakhmat Jaya Lahay $^{\mathrm{a}}$, Nurdin Mohamad ${ }^{\mathrm{b}}$
}

Jurusan Ilmu dan teknologi Kebumian, Universitas Negeri Gorontalo, Jln Jendral Sudirman, Kota Gorontalo 96128, Indonesia

\begin{tabular}{|c|c|}
\hline INFO & ABSTRACT \\
\hline $\begin{array}{l}\text { tatus artikel: } \\
\text { iterima: } 01-03-2020 \\
\text { isetujui: } 03-03-2020 \\
\text { 'ersedia online: } 04-03-2020 \\
\text { ata kunci: } \\
\text { eta Puzzle, Mobile, Augmented Reality, } \\
\text { Media, Pembelajaran Geografi }\end{array}$ & $\begin{array}{l}\text { Presentation of maps in paper form is still often done. The advancement of mobile } \\
\text { devices and the support of augmented reality technology are alternatives in making map } \\
\text { media presentations more interesting and interactive. This research aims to develop } \\
\text { media prototypes in the form of educational games based on mobile augmented reality. } \\
\text { Media development is carried out using a prototype approach. The developed media is } \\
\text { able to display 3D map objects properly based on the results of black box testing and beta } \\
\text { testing. Black box testing shows that the media functions as needed. Beta testing states } \\
\text { that this application can be accepted with the percentage of survey results is } 89.7 \% \text {. }\end{array}$ \\
\hline
\end{tabular}

Penulis korespondensi:

Rakhmat Jaya Lahay

Pendidikan Geografi, Gorontalo,

Indonesia

Email: rijlahay@ung.ac.id

DOI: $10.34312 /$ jgej.v1i1.4675

Copyright () 2020 JGEJ-UNG

All Rights Reserved.

\begin{abstract}
ABSTRAK
Penyajian peta dalam bentuk kertas masih sering dilakukan. Kemajuan perangkat mobile dan dukungan teknologi augmented reality menjadi alternatif dalam membuat sajian media peta lebih menarik dan interaktif. Penelitian ini bertujuan untuk mengembangkan prototipe media berbentuk game edukasi berbasis mobile augmented reality. Pengembangan media dilakukan dengan pendekatan prototipe. Media yang dikembangkan mampu menampilkan objek peta 3D secara baik berdasarkan hasil pengujian kotak hitam dan pengujian beta. Pengujian kotak hitam menunjukan bahwa media berfungsi sebagaimana yang diharapkan. Pegujian beta menyatakan bahwa aplikasi ini dapat diterima dengan persentase hasil survei adalah $89,7 \%$.
\end{abstract}

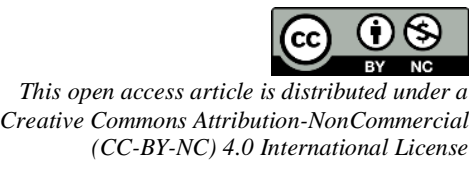

\section{Pendahuluan}

Geografi, sebagai salah satu cabang geosains (Båth, 1975), yang mempelajari fenomena yang ada dipermukaan bumi dan hubungannya dengan kepentingan manusia (Yunus, 2008). Visualisasi fenomena dari dunia nyata dapat dilakukan dengan menggunakan media peta. Peta dapat menjadi media yang baik untuk menjelaskan hubungan berbagai fenomena yang terjadi (Kraak \& Ferjan, 2007). Oleh karena itu, peta menjadi alat utama bagi pendidik untuk mengkomunikasikan data dan informasi geografis dalam pembelajaran geografi (Demiralp, 2007).

Selama ini penggunaan media peta dalam pembelajaran masih disajikan dalam bentuk peta kertas (paper map). Peta kertas ini hanya mampu menyajikan objek 2 dimensi (2D), dan terbatas dalam menyajikan objek 3 dimensi (3D). Ketersediaan peta digital yang dapat disajikan melalui teknologi mobile (smartphone), menjadi alternatif untuk mengatasi keterbatasan ini. Demikian pula dengan adanya teknologi komputer grafis augmented reality (AR), memungkinkan peta dapat disajikan secara 3D pada perangkat mobile. Kombinasi perangkat mobile dan teknik AR ini dapat dimanfaatkan untuk mengembangkan media pembelajaran yang interaktif, menarik dan mudah digunakan.

Menurut (R. T. Azuma, 1997) AR adalah integrasi visual objek virtual 3D kedalam lingkungan yang sesungguhnya secara real time. Lebih lanjut (R. Azuma et al., 2001) memberikan ciri-ciri sistem AR, yaitu: kombinasi antara objek maya dan nyata dalam lingkungan yang nyata, interaksi dengan objek secara real time, selaras batas antara objek virtual dan objek nyata. Dalam (Blanco-Pons et al., 2019) dinyatakan bahwa pelacakan objek dalam teknologi AR terdiri dari dua kelompok, yaitu pelacakan berbasis marker dan pelacakan markerless. 
Pengembangan mobile augmented reality (MAR) sebagai media pembelajaran telah banyak dilakukan. Penelitian oleh (Syawaludin, Gunarhadi, \& Rintayati, 2019) mengenai multimedia interaktif berbasis AR markerless untuk meningkatkan pemahaman pada pembelajaran sains bagi siswa sekolah dasar. (Khansa, 2017) mengembangkan aplikasi android berbasis AR markerless yang menyajikan objek 3D peta Indonesia dan landmark masing-masing daerah. Penelitian oleh (Liarokapis et al., 2005) mengembangkan peta puzzle $3 D$ untuk objek kampus universitas city menggunakan mobile dan teknik AR marker-based.

Pemanfaatan Mobile Augmented Reality (MAR) dalam pembelajaran masih dalam masa pertumbuhan, oleh karena itu perlu dilihat seberapa besar manfaatnya untuk menciptakan suasana belajar yang efektif (FitzGerald et al., 2014). Demikian juga game edukasi berbasis AR masih perlu untuk dieksplorasi lebih lanjut utamanya mengenai fitur, kekurangan dan kelebihannya (Bacca, Baldiris, Fabregat, Graf, \& Kinshuk, 2014). Aplikasi AR memungkinkan pengguna media terdiri dari beberapa orang dan saling bekerja sama untuk berinteraksi dengan objek geografi yang divisualisasikan (Hedley, Billinghurst, Postner, May, \& Kato, 2002).

Berdasarkan latar belakang tersebut, tujuan penelitian ini adalah untuk mengembangkan prototipe media pembelajaran berbasis Mobile Augmented Reality. Teknik AR yang dipilih adalah marker-based. Prototipe media ini berbentuk game edukasi (puzzle) yang dapat menyajikan peta topografi secara 3D.

\section{Metode}

Penelitian ini merupakan penelitian pengembangan (Research and Development). Pengembangan media dilakukan dengan menggunakan pendekatan prototipe (prototyping). Menurut (Pressman, 2005) pendekatan prototipe terdiri dari beberapa tahap, yaitu: identifikasi kebutuhan, desain, pembuatan prototipe, dan evaluasi. Pada tahap identifikasi kebutuhan dilakukan kegiatan untuk mendefinisikan tujuan pembuatan media, dan mengidentifikasi kebutuhan data dan perangkat keras dan perangkat lunak. Kebutuhan data diidentifikasi melalui studi dokumentasi, penelusuran internet, diskusi, wawancara dan kuisioner.

Tahap selanjutnya adalah membuat desain prototipe. Desain terdiri dari desain masukan, proses dan keluaran. Tahap pembuatan prototipe dimaksudkan untuk mengimplementasikan hasil desain menggunakan perangkat lunak pengembangan. Terakhir adalah tahap evaluasi (pengujian). Pengujian ini untuk memastikan bahwa prototipe yang dikembangkan sudah berjalan sesuai kebutuhan dan tujuan yang diharapkan.

\section{Hasil dan Pembahasan}

Media pembelajaran yang dikembangkan pada penelitian ini berbentuk prototipe. Prototipe media berupa game edukasi berbentuk peta puzzle dengan teknologi augmented reality. Game edukasi ini dapat dimainkan secara kolaboratif menggunakan perangkat mobile (smartphone). Objek geografi yang divisualisasikan secara 3D pada peta puzzle adalah topografi pulau Sulawesi.

\subsection{Kebutuhan Data}

Berdasarkan hasil identifikasi kebutuhan, pembuatan media berupa peta digital membutuhkan dua jenis data. Pertama adalah data SRTM 90m DEM Version 4, yang diunduh secara bebas dari laman http://srtm.csi.cgiar.org/. Data ini dibutuhkan untuk pembuatan model peta 3D elevasi permukaan bumi (topografi) digital. Format data tersimpan dalam tipe GeoTIFF, dengan resolusi spasial 90m. Data yang kedua adalah, wilayah pulau Sulawesi, dalam format tersimpan dalam tipe shapefile.

\subsection{Kebutuhan Perangkat}

Perangkat lunak dan perangkat keras serta fungsinya, yang digunakan pada pengembangan protipe media disajikan pada tabel 1 dan 2. Selain sistem operasi (Windows 10 Pro), perangkat lunak pengembangan yang digunakan bersifat gratis dan terbuka. 
Tabel 1. Daftar Perangkat Lunak

\begin{tabular}{ll}
\hline \multicolumn{1}{c}{ Perangkat Lunak } & \multicolumn{1}{c}{ Fungsi } \\
\hline Windows 10 Pro & $\begin{array}{l}\text { Mengoperasikan sumber daya baik itu perangkat } \\
\text { keras dan perangkat lunak (aplikasi) }\end{array}$ \\
\hline QGIS 3.4.14-Madeira & $\begin{array}{l}\text { Mengolah data spasial dan memodelkan objek 3D } \\
\text { topografi }\end{array}$ \\
\hline Blender & Memodifikasi objek 3D topografi \\
\hline Inkscape & Memodifikasi gambar tekstur untuk objek 3D \\
\hline Openspace3D & Membuat media Mobile Augmented Reality \\
\hline
\end{tabular}

Tabel 2. Daftar Perangkat Keras

\begin{tabular}{|c|c|}
\hline Perangkat Keras & Fungsi \\
\hline $\begin{array}{l}\text { Laptop hp AMD A6-9220 Redeon } \\
\text { R4, Ram 4GB }\end{array}$ & $\begin{array}{l}\text { Sebagai perangkat keras untuk instalasi sistem } \\
\text { operasi dan aplikasi lainnya }\end{array}$ \\
\hline Smartphone Xiaomi A6 & Menguji coba media \\
\hline
\end{tabular}

\subsection{Desain Masukan, Proses dan Keluaran}

Desain masukan berupa konstruksi peta puzzle, model data 3D, jenis dan tipe file yang akan digunakan. Tahapan ini dimulai dari pengolahan data geografis menggunakan aplikasi QGIS. QGIS memiliki tools yang menghasilkan vector grid dan model objek 3D geografi. Vektor grid merupakan struktur objek yang berbentuk kotak-kotak sebagai pola untuk membuat peta puzzle (lihat gambar 1a). Pola ini selanjutnya digunakan untuk membagi-bagi objek peta menjadi 9 potongan. Peta Sulawesi dipilih sebagai model 3D dan tersedia dalam format raster (data SRTM). Kenampakan 3D (gambar 1b) dihasilkan dari data ketinggian yang ada di data SRTM. Hasil pemodelan 3D ini yang digunakan pada tahap selanjutnya.
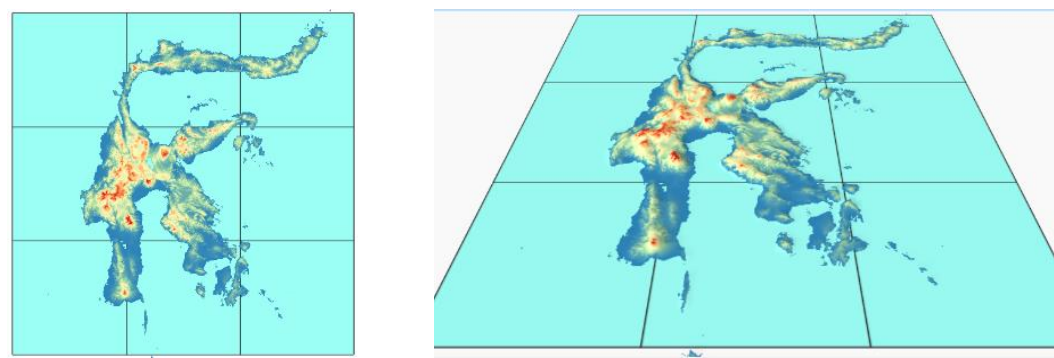

Gambar: 1a Tampilan Peta Sulawesi 2D; 1b. Tampilan 3D

Desain proses berupa proses yang terjadi ketika aplikasi menerima input. Jenis input dimaksud adalah adalah marker. Desain keluaran berupa peta 3D yang ditampilkan ketika marker teridentifikasi oleh aplikasi. Keluaran terdiri dari model objek 3D dan Gambar tekstur permukaan objek 3D. Kegiatan yang dilakukan pada tahap ini adalah melakukan modifikasi objek 3D. Terdapat perbedaan format file yang digunakan oleh aplikasi AR. Modifikasi yang dimaksud disini adalah melakukan konversi tipe file. Demikian juga pada tahap ini dilakukan modifikasi gambar yang akan digunakan sebagai tekstur objek 3D. Kedua keluaran ini dibuat dengan perangkat lunak Blender dan Inkscape.

\subsection{Pengembangan Mobile Augmented Reality}

Perangkat lunak yang digunakan untuk membuat protipe media adalah OpenSpace3D. OpenSpace3D merupakan platform yang gratis dan open-source, untuk membuat aplikasi AR. Perangkat ini mendukung pemrograman secara visual dengan system plugITs yang dimilikinya. Pemrograman visual ini sangat mudah bagi yang tidak memiliki kemampuan coding. Pengembangan media dimulai dengan memasukan scene model objek 3D yang dihasilkan dari tahap sebelumya kedalam aplikasi AR. Pengaturan scene berupa input scene berupa AR Capture dan AR marker dilakukan sesuai kebutuhan. Demikian juga dengan pengaturan 
skala, posisi objek, dan tekstur objek serta marker yang akan digunakan. Pengembangan prototipe media dengan pemrograman visual dapat dilihat pada gambar 2 .

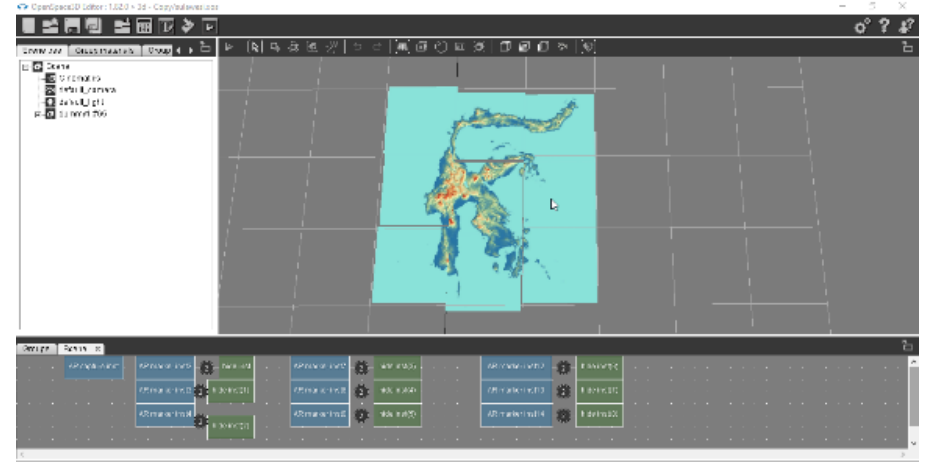

\section{Gambar 2 Pengembangan prototipe dengan pemrograman visual}

Marker berfungsi sebagai masukan pada aplikasi. Pembuatan marker dilakukan melalui aplikasi AR, sebanyak 9 jenis. Marker ini berfungsi sebagai penanda yang akan diindentifikasi oleh sistem untuk memicu munculnya objek peta permukaan bumi 3D. Setiap marker terhubung dengan salah satu potongan objek 3D. Jenis marker dan potongan objek 3D dapat ditampilkan pada gambar 3.

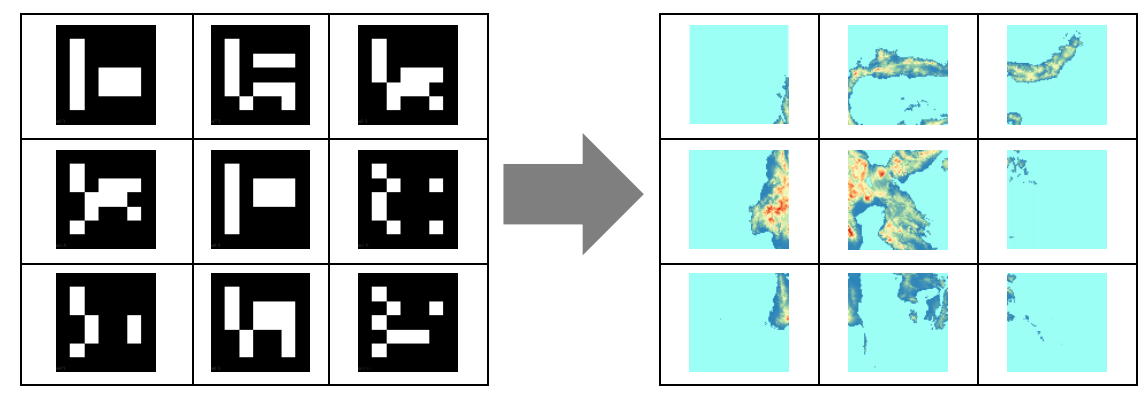

Gambar 3 Marker dan Tampilan Keluaran

\subsection{Pengujian}

Pengujian media dilakukan dengan 2 tahap, yaitu tahap pertama pengujian kotak hitam dan tahap kedua adalah pengujian beta (beta testing). Pengujian kotak hitam dimaksudkan untuk memastikan bahwa fungsi media telah sesuai dengan keluaran yang diharapkan. Demo pengujian dapat dilihat pada gambar 4, dapat pula dilihat pada link https://www.youtube.com/watch?v=PYryvtoG45c\&t=44s.

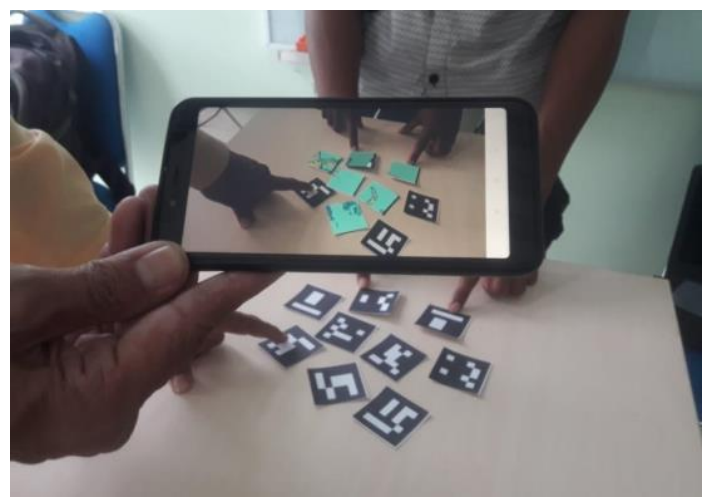

\section{Gambar 4 Demo Pengujian Aplikasi}

Apabila terdapat kesalahan pada saat pengujian, maka kembali pada tahap pengembangan untuk diperbaiki. Jenis kesalahan berupa sulitnya marker diindentifikasi, sehingga objek 3D tidak ditampilkan. Uji Coba media dilakukan dengan menggunakan perangkat mobile (Smartphone). Tahap pertama uji coba adalah 
melakukan import aplikasi kedalam perangkat mobile dan dilanjutkan dengan instalasi media. Selanjutnya, beberapa hal yang diuji ditampilkan pada tabel berikut:

Tabel 3. Hasil Pengujian Media

\begin{tabular}{cccc}
\hline No & Bentuk Pengujian & Hasil yang diharapkan & $\begin{array}{c}\text { Hasil } \\
\text { Pengujian }\end{array}$ \\
\hline 1 & Instalasi aplikasi & Aplikasi terpasang & Berhasil \\
\hline 2 & $\begin{array}{c}\text { Menjalankan aplikasi } \\
\text { (running) }\end{array}$ & $\begin{array}{c}\text { Aplikasi dapat dijalankan. Kamera } \\
\text { smartphone diaktifkan }\end{array}$ & Berhasil \\
\hline 3 & $\begin{array}{c}\text { Deteksi } \text { Marker } \text { saat awal } \\
\text { dijalankan }\end{array}$ & $\begin{array}{c}\text { Objek 3D dikenali dan tampil bertampalan } \\
\text { dengan marker }\end{array}$ & Berhasil \\
\hline 4 & $\begin{array}{c}\text { Deteksi } \text { Marker } \text { saat digeser } \\
\text { kedudukannya }\end{array}$ & $\begin{array}{c}\text { Objek 3D dikenali dan tampil bertampalan } \\
\text { dengan marker }\end{array}$ & Berhasil \\
\hline 5 & $\begin{array}{c}\text { Deteksi } \text { Marker } \text { saat diangkat } \\
\text { dari kedudukannya }\end{array}$ & $\begin{array}{c}\text { Objek 3D dikenali dan tampil bertampalan } \\
\text { dengan marker }\end{array}$ & Berhasil \\
\hline
\end{tabular}

\section{Sumber : Hasil Olah Data, 2020}

Pengujian tahap kedua Pengujian Beta (Beta Testing) dilakukan untuk menguji kemampuan media (aplikasi) oleh pengguna lain. Pengujian ini dilakukan kepada 13 mahasiswa Jurusan Ilmu dan Teknologi Kebumian Universitas Negeri Gorontalo. Mahasiwa diberi kesempatan untuk menggunakan smartphone yang telah terpasang aplikasi. Selanjutnya disajikan lembar kuisioner yang berisi 4 pertanyaan sebagaimana yang disajikan pada tabel 2 berikut. Pertanyaan pada kuisioner dan perhitungan hasil pengujian ini diadaptasi dari (Andrea, Lailiyah, Agus, \& Ramadiani, 2019) dengan modifikasi pada pertanyaannya. Bobot masingmasing penilaian adalah jawaban "Bagus" bernilai 3, "Cukup" bernilai 2, dan "Kurang" bernilai 1.

\section{Tabel 4. Hasil Pengujian Beta}

\begin{tabular}{rlcccc}
\hline \multirow{2}{*}{ No. } & \multirow{2}{*}{ Pertanyaan } & \multicolumn{3}{c}{ Penilaian } & \multirow{2}{*}{ Jumlah } \\
\cline { 3 - 5 } & & Bagus & Cukup & Kurang & \\
\hline 1 & Bagaimana tampilan aplikasinya? & 12 & 1 & 0 & 13 \\
\hline 2 & Bagaimana kemudahan menggunakannya? & 6 & 7 & 0 & 13 \\
\hline 3 & Bagaimana isi materi (topografi permukaan bumi)? & 11 & 2 & 0 & 13 \\
\hline 4 & Bagaimana tampilan objek 3 dimensinya? & 9 & 2 & 2 & 13 \\
\hline \multicolumn{2}{c}{ Jumlah } & 38 & 12 & 2 & 52 \\
\hline
\end{tabular}

\section{Sumber : Hasil Olah Data, 2020}

Persentase rata-rata jawaban responden diperoleh dari perhitungan berikut:

Persentase Jawaban $=\frac{(38 \times 3)+(12 \times 2)+(2 \times 1)}{52 \times 3} \times 100 \%=89,7 \%$

Berdasarkan hasil perhitungan tersebut diperoleh nilai sebesar 89,7\%. Menurut (Andrea et al., 2019) bahwa persentase nilai diatas $50 \%$ berarti media dapat diterima/valid.

\section{Kesimpulan}

Prototipe media peta puzzle $3 D$ berbasis mobile augmented reality dengan teknik marker-based telah berhasil dibuat. Peta topografi secara 3D dapat disajikan dengan baik berdasarkan hasil pengujian. Pengujian kotak hitam, menunjukan bahwa keseluruhan fungsi aplikasi berjalan dengan baik. Pengujian beta menunjukan hasil $89,7 \%$ yang berarti bahwa media dapat diterima.

\section{Referensi}

Andrea, R., Lailiyah, S., Agus, F., \& Ramadiani, R. (2019). "Magic Boosed" an elementary school geometry textbook with marker-based augmented reality. TELKOMNIKA (Telecommunication Computing 
Electronics and Control), 17(3), 1242. https://doi.org/10.12928/telkomnika.v17i3.11559

Azuma, R., Baillot, Y., Behringer, R., Feiner, S., Julier, S., \& MacIntyre, B. (2001). Recent advances in augmented reality. IEEE Computer Graphics and Applications. https://doi.org/10.1109/38.963459

Azuma, R. T. (1997). A survey of augmented reality. Presence: Teleoperators and Virtual Environments. https://doi.org/10.1162/pres.1997.6.4.355

Bacca, J., Baldiris, S., Fabregat, R., Graf, S., \& Kinshuk. (2014). Augmented reality trends in education: A systematic review of research and applications. Educational Technology and Society.

Båth, M. (1975). Introduction to Seismology. Geophysical Journal of the Royal Astronomical Society. https://doi.org/10.1111/j.1365-246X.1975.tb01612.x

Blanco-Pons, S., Carrión-Ruiz, B., Duong, M., Chartrand, J., Fai, S., \& Lerma, J. L. (2019). Augmented Reality markerless multi-image outdoor tracking system for the historical buildings on Parliament Hill. Sustainability (Switzerland). https://doi.org/10.3390/su11164268

Demiralp, N. (2007). Geography Education Through Maps. Bulgarian Journal of Science and Education Policy, 1(1).

FitzGerald, E., Ferguson, R., Adams, A., Gaved, M., Mor, Y., \& Thomas, R. (2014). Augmented Reality and Mobile Learning. International Journal of Mobile and Blended Learning. https://doi.org/10.4018/ijmbl.2013100103

Hedley, N. R., Billinghurst, M., Postner, L., May, R., \& Kato, H. (2002). Explorations in the use of augmented reality for geographic visualization. Presence: Teleoperators and Virtual Environments. https://doi.org/10.1162/1054746021470577

Khansa, R. A. (2017). Pengembangan Aplikasi "Indonesian Landmark" Berbasis Android dengan Teknologi Augmented Reality. KOPERTIP: Jurnal Ilmiah Manajemen Informatika Dan Komputer, 01(02), 7784. Retrieved from http://jurnal.kopertipindonesia.or.id/ojs/index.php/kopertip/article/view/12/14

Kraak, M.-J., \& Ferjan, O. (2007). Kartografi: Visualisasi Data Geospasial (Terjemahan) (2nd ed.). Yogyakarta: Gadjah Mada University Press.

Liarokapis, F., Greatbatch, I., Mountain, D., Gunesh, A., Brujic-Okretic, V., \& Raper, J. (2005). Mobile Augmented Reality Techniques for GeoVisualisation. Ninth International Conference on Information Visualisation (IV'05), 745-751. https://doi.org/10.1109/IV.2005.79

Pressman, R. S. (2005). Software Engineering: A Practitioner's Approach (6th ed.). Retrieved from https://books.google.co.id/books?id=7c6rQgAACAAJ

Syawaludin, A., Gunarhadi, \& Rintayati, P. (2019). Enhancing Elementary School Students' Abstract Reasoning in Science Learning through Augmented Reality-Based Interactive Multimedia. Jurnal Pendidikan IPA Indonesia, 8(2), 288-297. https://doi.org/10.15294/jpii.v8i2.19249

Yunus, H. S. (2008). Konsep dan Pendekatan Geografi-memaknai hakekat keilmuannya. Sarasehan Forum Pimpinan Perguruan Tinggi Geografi Indonesia. Yogyakarta. 